\title{
FOLIA
} MALACOLOGICA

\section{ŚLIMAKI LĄDOWE (GASTROPODA TERRESTRIA) DOLINY MROGI I PARKÓW PODWORSKICH POŁOŻONYCH W SĄSIEDZTWIE RZEKI}

\author{
ANNA SULIKOWSKA \\ Chair of Invertebrate Zoology and Hydrobiology, University of Łódź, Banacha 12/16, 90-237 Łódź, Poland \\ (e-mail: sulik@biol.uni.lodz.pl) \\ ABSTRACT: 39 land gastropod species have been recorded from the Mroga river valley (central Poland). Manor \\ parks adjoining the river are important for preservation of the local malacofauna.
}

KEY WORDS: terrestrial gastropods, faunistics, Poland

\section{WSTEP}

Dolina Mrogi leży na południowo-zachodnim krańcu Niziny Mazowieckiej. Jej południowa część, znajdująca się w strefie wysoczyznowej (Wzniesienia Łódzkie) ma urozmaiconą polodowcowa rzeźbę. Część północna (Równina Łowicko-Błońska) jest płaska, podmokła i prawie wylesiona. Mroga nie została uregulowana i mimo znacznego rozwoju rolnictwa w jej dolinie zachowało się wiele naturalnych siedlisk, szczególnie podmokłych. W dolinie i na jej obrzeżach położone są parki podworskie pochodzące z XVIII/XIX wieku, zakładane w stylu angielskim. W dolnym biegu Mrogi obiekty te, jako namiastki lasów na obszarze prawie bezleśnym, mają duże znaczenie dla zachowania bioróżnorodności (OLACZEK 1971). Wyróżnia się przyrodniczo

\section{WYKAZ STANOWISK}

1. Rezerwat „Gałków” (kwadrat UTM DC13); 2. Kolonia Gałkówek: cmentarz ewangelicki, las Pustułka (DC13); 3. Przanowice: łęg poniżej mostu (DC13); 4. Bogdanka: zarośla poniżej mostu, skarpa nad stawem (DC13); 5. Rochna: wilgotny las poniżej mostu, las mieszany z dębem i sosną (DC13); 6. Lisowice: park dworski; 7. Tworzyjanki: park dworski (DC13); 8. Bronowice: brzeg rzeki, łąka nad rzeką, sucha skarpa park w Walewicach, w skład którego wchodzi fragment prawie naturalnego łęgu z 80-150-letnim drzewostanem wiązowo-jesionowym i bujnym runem.

Celem niniejszej pracy było zestawienie listy gatunków ślimaków lądowych doliny Mrogi. Szczególną uwagę zwrócono na faunę parków podworskich położonych w pobliżu rzeki. Poza inwentaryzacją stanowisk ślimaka winniczka (PIECHOCKI, dane niepublikowane) teren doliny nie był wcześniej badany pod względem malakologicznym. Również pozostała część Niziny Mazowieckiej, poza dokładniej zbadanymi okolicami Warszawy (JANKOWSKI 1933, 1938, POLIŃSKI 1917) i Skierniewic (DZIĘCZKOWSKI 1988), należy do słabiej poznanych pod względem malakofauny obszarów kraju (RIEDEL 1981, 1988).

(DC14); 9. Wągry: łęg nad rzeką (DC14); 10. Rogów: łęg poniżej stawu, park dworski (DC14); 11. Olsza: łąki i zarośla powyżej mostu w Olszy (DC14); 12. Mroga Dolna: brzeg rzeki, łęg, grobla, skarpa, turzycowisko (DC14); 13. Kołacin: park dworski, łąka nad rzeką, las mieszany na skarpie, bór mieszany (DC14); 16. Kołacinek: cmentarz, park dworski (DC14); 15. Dmosin: łąka powyżej mostu (DC15); 16. Osiny: park 
dworski (DC15); 17. Głowno: zieleń miejska, cmentarz (DC15); 18. Rezerwat „Zabrzeźnia” (DC05); 19. Domaradzyn: park dworski (DC06); 20. Ziewanice: zarośla na brzegu rzeki (DC06); 21. Stary Waliszew: otoczenie kościoła, cmentarz (DC06); 22. Psary: park dworski (DC06); 23. Łuby Bielawskie: zarośla na brzegu rzeki (DC06); 24. Mroga k. Bielaw: park dworski (DC06); 25. Bielawy: cmentarz (DC07); 26. Walewice: park pałacowy, pastwisko na brzegu rzeki (DC07); 27. Marylin: zarośla przy zniszczonym moście na Mrodze (DC07).

\section{LISTA STWIERDZONYCH GATUNKÓW}

1. Carychium minimum O. F. Müller, 1774 (stanowiska: 5, 12); 2. Carychium tridentatum (Risso, 1826) (3, 5, 12); 3. Succinea (Succinea) putris (Linnaeus, 1758) (3, 8, 9, 11-13, 25, 26); 4. Cochlicopa lubrica (O. F. Müller, 1774) (2, 3, 5, 7-10, 12-15, 17, 20, 23, 24, 26, 27); 5. Cochlicopa lubricella (Porro, 1838) (2, 8, 12); 6. Cochlicopa nitens (Gallenstein, 1852) (12); 7. Vertigo (Vertigo) pusilla O. F. Müller, 1774 (13); 8. Vertigo (Vertigo) pygmaea (Draparnaud, 1801) $(8,12,13)$; 9. Pupilla muscorum (Linnaeus, 1758) (26); 10. Vallonia pulchella (O. F. Müller, 1774) (2, 7, 8, 10, 12-16, 20, 23, 24, 26); 11. Vallonia excentrica Sterki, 1893 (6, 12, 13, 24); 12. Vallonia costata (O. F. Müller, 1774) (6, 7, 10, 12, 15-17, 25- 27); 13. Punctum pygmaeum (Draparnaud, 1801) (12); 14. Discus (Gonyodiscus) rotundatus (O. F. Müller, 1774) (5, 7, 18); 15. Discus (Discus) ruderatus (Férussac, 1821) (13); 16. Arion (Mesarion) subfuscus (Draparnaud, 1805) (1, 3, 4, 13); 17. Arion (Carinarion) circumscriptus Johnston, 1926 (2, 4, 5, 12, 19, 21, 26); 18. Arion (Carinarion) fasciatus (Nilsson, 1822) (24); 19. Vitrina pellucida (O. F. Müller, 1774) (2-8, 10-18, 21, 23-26); 20. Vitrea crystallina (O. F. Müller, 1774) $(3,5,8-13,15,26) ; 21$. Aegopinella nitidula (Dra- parnaud, 1805) (3-5, 8, 10, 11); 22. Nesovitea hammonis (Ström, 1765) (2, 3, 5, 7, 8, 10-13, 15, 18, 26); 23. Nesovitrea petronella (L. Pfeiffer, 1853) (3, 9, 11-13); 24. Zonitoides nitidus(O. F. Müller, 1774) (2, 3, 5, 8, 9, 11-15, 17, 20, 24-27); 25. Limax (Limax) cinereoniger Wolf, 1803 (18); 26. Lehmannia marginata (O. F. Müller, 1774) (1); 27. Deroceras (Deroceras) sturanyi (Simroth, 1894) $(2,17) ; 28$. Deroceras (Agriolimax) agreste (Linnaeus, 1758) (1, 2, 5); 29. Deroceras (Agriolimax) reticulatum (O. F. Müller, 1774) (4, 5, 8, 12, 14, 15, 17, 19, 21, 25); 30. Euconulus fulvus (O. F. Müller, 1774) $(2,5,2,13)$; 31. Bradybaena fruticum (O. F. Müller, 1774) $(26,27)$; 32. Perforatella (Perforatella) bidentata (Gmelin, 1791) (2, 3, 9, 11-13, 15, 26); 33. Perforatella (Monachoides) incarnata (O. F. Müller, 1774) (2-7, 9-12, 18); 34. Perforatella (Pseudotrichia) rubiginosa (A. Schmidt, 1853) (17, 20, 23, 26); 35. Trichia (Trichia) hispida (Linnaeus, 1758) (25); 36. Euomphalia strigella (Draparnaud, 1801) (5-7, 16, 26); 37. Cepaea (Cераea) hortensis (O. F. Müller, 1774) (4-6, 9-11); 38. Cepaea (Cepaea) nemoralis (Linnaeus, 1758) $(17,21)$; 39. Helix pomatia Linnaeus, 1758 ( 2, 16, 17, 19-21).

\section{DYSKUSJA}

Trzy ze stwierdzonych gatunków nie były podane przez RIEDLA (1988) z Niziny Mazowieckiej: Cochlicopa nitens, Aegopinella nitidula i Lehmannia marginata. Cochlicopa nitens odnotowano wcześniej z okolic Skierniewic (DZIECZKOWSKI 1988). Gatunek ten zamieszkuje nizinne bagna i moczary na podłożu bogatym w wapń. Zasiedla prawdopodobnie cały kraj, lecz jest rzadki (RIEDEL 1988). Lehmannia marginata to gatunek sporadycznie spotykany w Polsce Środkowej, ale notowany z krain sąsiadujących z Niziną Mazowiecką (WIKTOR 1989).

Aegopinella nitidula zebrano na 6 stanowiskach w górnej części doliny Mrogi (Przanowice, Bogdanka, Rochna, Bronowice, Rogów i Olsza); gatunek ten występował najliczniej w trzech pierwszych miejscowościach. Ae. nitidula (zebrano łącznie 117 osobników) występowała w wilgotnej ściółce olchowych zarośli tuż nad rzeką. Jest to gatunek zachodnio- i północno- zachodnio-europejski, zaliczany do elementu subatlantyckiego (RIEDEL 1988). Prawdopodobnie występuje też na Litwie, Łotwie i w Estonii, a także w okolicach St. Petersburga, jednak część danych z tego obszaru może odnosić się do Ae. minor (Stab.). RIEDEL (1988) podaje, że zasięg Ae. nitidula w Polsce kończy się na wschodzie mniej więcej na linii Gdańsk - Toruń - Ostrów Wielkopolski - Nysa. Niektóre z cytowań z Pojezierza Pomorskiego i Niziny Wielkopolsko-Kujawskiej nie sa pewne, gdyż materiał oznaczano tylko konchiologicznie. W Górach Świętokrzyskich PIECHOCKI (1981) znalazł puste muszle należące prawdopodobnie do Ae. nitidula. Jeśli oznaczenie to zostanie potwierdzone badaniami anatomicznymi (RIEDEL 1988), będzie to wyspowe stanowisko reliktowe. Znalezienie Ae. nitidula w dolinie Mrogi przesuwa zasięg tego gatunku w Polsce Środkowej o blisko $150 \mathrm{~km}$ na wschód (por. mapa w: KeRNEY et al. 1983: 341). 
W 8 parkach podworskich leżących w sąsiedztwie rzeki znaleziono 21 gatunków ślimaków lądowych (Tabela 1), tj. 56\% gatunków stwierdzonych na badanym terenie. Większość parków sąsiaduje bezpośrednio z rzeką, a w ich skład wchodzą fragmenty naturalnych lasów łęgowych i grądowych. Parki podworskie zachowały pozostałości roślinności doliny rzecznej, jednakże w ciągu ostatnich 50 lat wiele obiektów uległo dewastacji i było wykorzystywanych w sposób niezgodny z przeznaczeniem. Wypas i wydeptywanie miały niekorzystny wpływ na faunę ślimaków. Z drugiej strony ekspansja roślinności ruderalnej i zaniechanie zabiegów ogrodniczych sprzyjało rozwojowi populacji gatunków synantropijnych.

Najbogatszą malakofaunę (14 gatunków) ma park w Walewicach. W parkach w Rogowie i w Osinach, leżących daleko od cieków wodnych (około $500 \mathrm{~m}$ ), mimo dokładnych poszukiwań stwierdzono niewiele gatunków ślimaków. Poza Vallonia excentrica, wszystkie były wcześniej podawane $\mathrm{z}$ bogatszych malakologicznie parków zachodniej części kraju (KĘDRA 1972, KORALEWSKA 1979).

Parki doliny Mrogi zasiedlają gatunki o zróżnicowanych wymaganiach ekologicznych (podział wg LOŽKA (1964) i RIEDLA (1988)): od wilgociolubnych, związanych z brzegiem rzeki (Succinea putris, Zonitoides nitidus, Perforatella rubiginosa), poprzez gatunki terenów otwartych (rodzaj Vallonia), aż po synantropijne Arion fasciatus, Deroceras reticulatum i Discus rotundatus. Najliczniejszą grupę stanowią gatunki mezofilne, występujące zarówno w lasach jak i na terenach otwartych o różnej wilgotności oraz w środowiskach synantropijnych (Cochlicopa lubrica, Vitrina pellucida, Nesovitrea hammonis), a także gatunki leśno-zaroślowe, spotykane również w ogrodach i parkach (Vitrina crystallina, Bradybaena fruticum, Perforatella incarnata, Cepaea

Tabela 1. Ślimaki stwierdzone w parkach podworskich (P1 - Lisowice, P2 - Tworzyjanki, P3 - Rogów, P4 - Kołacin, P5 Kołacinek, P6 - Osiny, P7 - Mroga, P8 - Walewice); B - liczba gatunków stwierdzonych w danym parku; A - liczba parków, w których stwierdzono dany gatunek; X - żywe osobniki; R - muszle

Table 1. Gastropods found in manor parks (P1 - Lisowice, P2 - Tworzyjanki, P3 - Rogów, P4 - Kołacin, P5 - Kołacinek, P6 Osiny, P7 - Mroga, P8 - Walewice); B - number of species found in a park; A - number of parks in which a species was found; $\mathrm{X}$ - live specimens; $\mathrm{R}$ - shells

\begin{tabular}{|c|c|c|c|c|c|c|c|c|c|}
\hline \multirow{2}{*}{ Gatunek } & \multicolumn{9}{|c|}{ Parki } \\
\hline & $\mathrm{P} 1$ & $\mathrm{P} 2$ & P3 & $\mathrm{P} 4$ & P5 & $\mathrm{P} 6$ & $\mathrm{P} 7$ & P8 & A \\
\hline Succinea putris & & & & $\mathrm{X}$ & $\mathrm{X}$ & & & $\mathrm{X}$ & 2 \\
\hline Cochlicopa lubrica & & $\mathrm{X}$ & $\mathrm{X}$ & $\mathrm{X}$ & $\mathrm{X}$ & & $\mathrm{X}$ & $\mathrm{X}$ & 6 \\
\hline Vallonia costata & $\mathrm{X}$ & $\mathrm{X}$ & $\mathrm{X}$ & & & $\mathrm{X}$ & & $\mathrm{X}$ & 5 \\
\hline Vallonia pulchella & & $\mathrm{X}$ & $\mathrm{X}$ & $\mathrm{X}$ & $\mathrm{X}$ & $\mathrm{X}$ & $\mathrm{X}$ & $\mathrm{X}$ & 7 \\
\hline Vallonia excentrica & $\mathrm{X}$ & & & & & & $\mathrm{X}$ & & 2 \\
\hline Discus ruderatus & & & & $\mathrm{X}$ & & & & & 1 \\
\hline Discus rotundatus & & $\mathrm{R}$ & & & & & & & 1 \\
\hline Arion circumscriptus & & & & & & & & $\mathrm{X}$ & 1 \\
\hline Arion fasciatus & & & & & & & $\mathrm{X}$ & & 1 \\
\hline Vitrina pellucida & $\mathrm{X}$ & $\mathrm{X}$ & $\mathrm{X}$ & $\mathrm{X}$ & $\mathrm{x}$ & $\mathrm{X}$ & $\mathrm{X}$ & $\mathrm{X}$ & 8 \\
\hline Vitrea crystallina & & & & $\mathrm{X}$ & & & & $\mathrm{X}$ & 2 \\
\hline Nesovitrea hammonis & & $\mathrm{X}$ & $\mathrm{X}$ & & & & & $\mathrm{X}$ & 3 \\
\hline Zonitoides nitidus & & & & $\mathrm{X}$ & $\mathrm{X}$ & & $\mathrm{X}$ & $\mathrm{X}$ & 4 \\
\hline Deroceras reticulatum & & & & & $\mathrm{X}$ & & $\mathrm{X}$ & & 2 \\
\hline Bradybaena fruticum & & & & & & & & $\mathrm{X}$ & 1 \\
\hline Perforatella bidentata & & & & $\mathrm{X}$ & & & & $\mathrm{X}$ & 2 \\
\hline Perforatella incarnata & $\mathrm{X}$ & $\mathrm{X}$ & & & & & & & 2 \\
\hline Perforatella rubiginosa & & & & & & & & $\mathrm{X}$ & 1 \\
\hline Euomphalia strigella & $\mathrm{X}$ & $\mathrm{X}$ & & & & $\mathrm{X}$ & & $\mathrm{R}$ & 4 \\
\hline Cepaea hortensis & $\mathrm{X}$ & & & & & & & & 1 \\
\hline Helix pomatia & & & & & & $\mathrm{X}$ & & & 1 \\
\hline $\mathrm{B}$ & 7 & 9 & 5 & 9 & 7 & 5 & 7 & 14 & \\
\hline
\end{tabular}


hortensis i Helix pomatia). Discus ruderatus, gatunek wyłącznie leśny (RIEDEL \& WIKTOR 1974), został stwierdzony nad Mrogą tylko na terenie parku w Kołacinie. Typowo leśne są także Arion circumscriptus, Perforatella bidentata i Euomphalia strigella. Pierwsze dwa żyją w wilgotnych olszynach, trzeci natomiast spotykany jest w widnych i dość suchych lasach i zaroślach. Zachowane parki pełnią w pewnym stopniu rolę refu-

\section{PIŚMIENNICTWO}

DZIĘCZKOWSKI A. 1988. Zespoły ślimaków (Gastropoda) zbiorowisk leśnych Polski. Studium ekologiczne. Prace Komisji Biologicznej PTPN 68: 1-117.

JANKOWSKI A. 1933. Mięczaki Warszawy. Sprawozdania Komisji Fizjograficznej PTPN 67: 99-114.

JANKOWSKI A. 1938: Mięczaki Warszawy (Uzupełnienie). Sprawozdania Komisji Fizjograficznej PTPN 71: 83-86.

Kerney M. P., Cameron R. A. D., Jungbluth J. H. 1983. Die Landschnecken Nord- und Mitteleuropas. Verlag Paul Parey, Hamburg-Berlin.

KĘDRA H. 1972. Mięczaki (Mollusca) Ziemi Chodzieskiej. Przyroda Polski Zachodniej 9: 48-58.

KORALEWSKA E. 1979. Ślimaki (Gastropoda) Ziemi Wrzesińskiej. Badania fizjograficzne nad Polską zachodnią, Ser. C, 32: 105-113.

LOŽEK V. 1964. Quartärmollusken der Tschechoslowakei. Rozpr. Ustr. Ust. Geol. 31. Verlag der Tschechoslowakischen Akademie der Wissenschaften, Praha.

\section{SUMMARY}

\section{TERRESTRIAL SNAILS (GASTROPODA TERRESTRIA) OF THE MROGA RIVER VALLEY (W MAZOWIAN LOWLAND) AND THE MANOR PARKS IN ITS VICINITY}

Thirty nine species of terrestrial gastropods were found along the Mroga river valley (central part of Poland, W Mazovian Lowland). Aegopinella nitidula (Drap.) was found at 6 localities; these are the first records from central Poland, east of the line Gdańsk - gium dla malakofauny leśnej, jednakże ich najliczniejszymi mieszkańcami są ślimaki o dużym zakresie tolerancji ekologicznej oraz gatunki synantropijne.

\section{PODZIĘKOWANIA}

Pragnę podziękować Panu Prof. dr hab. Adolfowi RiedloWI (Warszawa)za anatomiczne sprawdzenie oznaczeń Aegopinella nitidula.

OLACZEK R. 1971. Przewodnik po województwie Łódzkim. LOP, Warszawa.

PIECHOCKI A. 1981. Współczesne i subfosylne mięczaki (Mollusca) Gór Świętokrzyskich. Acta Univ. Lodziensis, Łódź.

Poliński W. 1917. Materyały do fauny malakozoologicznej Królestwa Polskiego, Litwy i Polesia. Pr. TN Warsz. 27: $1-130$.

Riedel A. 1981. Mięczaki (Mollusca). W: Stan zbadania fauny Polski. Przegląd Zoologiczny 25: 251-257.

RIEDEL A. 1988. Ślimaki lądowe. Gastropoda terrestra. Katalog Fauny Polski 46, PWN, Warszawa.

RIEDEL A., WikTOR A. 1974. Arionacea ślimaki krążałkowate i ślinikowate (Gastropoda: Stylommatophora). Fauna Polski 2. PWN, Warszawa.

WIKTOR, A. 1989: Ślimaki pomrowiokształtne (Gastropoda: Stylommatophora). Fauna Polski 12. PWN, Warszawa.

Toruń - Ostrów Wielkopolski - Nysa (UTM grid squares DC13, DC14) and thus the actual distribution border of the species was shifted $150 \mathrm{~km}$ eastwards. Other interesting species are Cochlicopa nitens (Gall.) - a marsh-dwelling calciphile, and Lehmannia marginata (Müll.) which is rare in the central part of the country. Manor parks adjoining the river, with their mosaic of habitats, are of significance for preserving the woodland fauna. 